\title{
DETERMINATION OF GRAY ZONE RANGE IN HBSAg TEST AND ITS IMPLICATION FOR HBsAg CONFIRMATION TEST
}

\author{
Vina Zakiah Latuconsina, Irda Handayani, Asvin Nurulita, Uleng Bahrun \\ Department of Clinical Pathology, Faculty of Medicine, Hasanuddin University/Wahidin Sudirohusodo Hospital, Makassar, \\ Indonesia. E-mail: vinaza.vinaza@gmail.com
}

\begin{abstract}
Hepatitis is an inflammation of liver cells caused by infection (virus, bacteria, paracytes), medication, alcohol consumption, excessive lipid and autoimmune disease. Increasing method (sensitivity) of HBsAg test is often followed by a lot of false positive test results, which need a confirmation test which takes a longer time and higher cost so that it is needed to determine an optimal gray zone range for a confirmation test. This analytical cross-sectional study was held at the Clinical Pathology Laboratory of the Dr.Wahidin Sudirohusodo Hospital Makassar. The subjects were specimens which HBsAg value was within 0.06-1 COI. Specimens were examined using HBsAg confirmation test. Over 49 samples collected there were 32 reactive and 17 nonreactive. 14 out of 32 reactive samples (43.8\%) were confirmed as negative (false positive) by HBsAg confirmation test and 3 out of 17 non-reactive samples (17.6\%) were confirmed as positive (false negative). Chi-square test showed a significant correlation between $\mathrm{HBsAg}$ value and $\mathrm{HBsAg}$ confirmation test value $(\mathrm{p}=0.009)$. Chisquare test with some intervals with $\alpha=1 \%$ showed that the interval of HBsAg value $0.13-0.17 \mathrm{COI}$ was the interval with the lowest significant value $(p=0.004)$. This subsequent interval was recommended as the gray zone range. The range $0.13-0.17$ was most optimal as HBsAg gray zone to determine the need for a confirmation test. A further study with larger samples is suggested.
\end{abstract}

Key words: HBsAg, HBsAg confirmation test, gray zone, hepatitis B

\section{INTRODUCTION}

Hepatitis is an inflammation of liver cells caused by infections (viruses, bacteria and paracytes), drugs, alcohol consumption, excess fat, as well as autoimmune diseases. The etiology of hepatitis $B$ is the hepatitis $B$ virus from a DNA virus group with an incubation period of 15-180 days. One of hepatitis B, Viral Hepatitis B (VHB), can be found in blood, semen, cervicovaginal secretions, saliva, other body fluids. ${ }^{1-3}$

Viral Hepatitis B (VHB) infection, moreover, has become a world health problem. About 2 billion people worldwide suffer from chronic hepatitis and $15 \%$ of patients die from its complications, such as cirrhosis and hepatic carcinoma. ${ }^{1,4}$

One of the important serologic markers of VHB infection is Hepatitis B surface antigen ( $\mathrm{HBsAg}$ ). Positive $\mathrm{HBsAg}$ indicates that VHB infection stimulates the formation of anti-HBV antibodies. Accurate detection, however, is still essential for early diagnosis and therapy. ${ }^{4-6}$

In recent years, many new methods have been found to detect $\mathrm{HBsAg}$, but increased sensitivity is often accompanied by many false positive results. Therefore, reactive samples are often repeatedly tested with the same test and or confirmation test. This procedure aims to ensure the reliability of results. The difference in $\mathrm{HBsAg}$ detection is primarily found in samples with weakly reactive results. However, repetition of the same test can take time and high cost so that a range of gray-zone values is required to determine whether confirmation test is needed or not. ${ }^{4,5}$ Thus, HBsAg confirmation test can be used to confirm the presence of $\mathrm{HBsAg}$ in positive serum or plasma.,

Current commercial HBsAg tests have emphasized the need for confirmatory tests for reactive HBsAg results. European and North American countries even have established a diagnostic protocol of 
HBV infection, repeating and confirming test results if any specimens result is borderline or reactive. ${ }^{4,9}$

A research conducted by Fletcher et al. argues that HBsAg values to be confirmed are weak reactive values since confirmatory tests are not important to conduct on high reactive HBsAg values. Another previous research conducted by Shao et al., then evaluated the application of a confirmatory tests for $\mathrm{HBsAg}$ detection by using Electro Chemilumiluminescence Immunoassay (ECLIA) method to establish a grayzone requiring confirmatory test. In short, results of both previous type of researches claimed that confirmation tests are important for weakly reactive $\mathrm{HBsAg}$ results with 1.0-4.0 COI values. ${ }^{4,10}$ As a result, this research aimed to determine $\mathrm{HBsAg}$ gray zone value range at the Clinical Pathology and Laboratory Installation of the Dr. Wahidin Sudirohusodo Hospital in Makassar based on confirmation test results.

\section{METHODS}

The research was conducted with a crosssectional study design. The population of this research consisted of all the specimens of patients having HBsAg test at the Clinical Pathology and Laboratory Installation of the Dr. Wahidin Sudirohusodo Hospital in Makassar from October 2015 to July 2016. Samples of this research also included all specimens with $\mathrm{HBsAg}$ values in temporary gray-zone range determined by the researchers $\{(0.06-1$ Cut-off Index (COI) $\}$ which would then be tested to confirm those $\mathrm{HBsAg}$ values. The temporary gray-zone range was made by the researchers based on the evaluation of $\mathrm{HBsAg}$ values that were not consistent at the Clinical Pathology and Laboratory Installation of the Dr. Wahidin Sudirohusodo Hospital in Makassar.

Next, HBsAg detection was qualitatively performed using serum/plasma samples measured by ELFA (Vidas ${ }^{\circledR}$ HBsAg Ultra) method with reactive values of $\geq 0.13 \mathrm{COI}$ and non-reactive ones of $<0.13 \mathrm{COI}$. HBsAg Confirmation test then was conducted using Vidas ${ }^{\circledR}$ HBsAg Ultra Confirmation reagent with Specific antibody neutralization method to confirm the presence of hepatitis $B$ antigen in serum/plasma of the patients. Afterward, results of the $\mathrm{HBsAg}$ confirmation test were classified into reactive ones if the results were the same with or more than $50 \%$. Meanwhile, those results were classified into non-reactive if the results were less than $50 \%$.

After that, the Chi-Square test was carried out to analyze the correlation of the HBsAg test results and the confirmatory test results. Various ranges of
HBsAg values then were made based on data distribution and analyzed by the Chi-Square test at $\alpha$ values of $5 \%$ and $1 \%$ to obtain the gray-zone range.

\section{RESULTS AND DISCUSSION}

The number of male patients in those fortynine research samples having $\mathrm{HBsAg}$ test was higher $(59.18 \%)$ than females as depicted in Table 1.

Table 1. Characteristics of the research samples

\begin{tabular}{|c|c|c|}
\hline Variables & $n=49$ & $\%$ \\
\hline \multicolumn{3}{|l|}{ Sex } \\
\hline Male & 29 & 59.2 \\
\hline Female & 20 & 40.8 \\
\hline \multicolumn{3}{|l|}{ Age (years) } \\
\hline$<20$ & 0 & 0 \\
\hline $20-39$ & 4 & 8.2 \\
\hline $40-59$ & 27 & 55.1 \\
\hline$\geq 60$ & 18 & 36.7 \\
\hline \multicolumn{3}{|l|}{ HBsAg values (COI) } \\
\hline Non-reactive $(<0.13)$ & 17 & 34.7 \\
\hline Reactive $\quad(\geq 0.13)$ & 32 & 65.3 \\
\hline \multicolumn{3}{|l|}{ HBsAg confirmation test } \\
\hline (\%) & 28 & 57.1 \\
\hline Non-reactive $(<50 \%)$ & 21 & 42.9 \\
\hline Reactive & & \\
\hline
\end{tabular}

Moreover, Table 2 illustrated that there were thirty-two samples having reactive $\mathrm{HBsAg}$ values $(\geq 0.13)$. However, after the HBsAg confirmation test, there were only eighteen samples (56.2\%) confirmed to have reactive values (confirmed), while the other fourteen samples $(43.8 \%)$ were negative (not confirmed). On the other hand, there were seventeen samples with non-reactive $\mathrm{HBsAg}$ value $(<0.13)$. Nevertheless, after the HBsAg confirmation test, there were only fourteen samples $(82.4 \%)$ confirmed to have negative values (confirmed), while the other three samples (17.6\%) confirmed to have reactive values (not confirmed). Table 2 also indicated that there was a correlation between $\mathrm{HBsAg}$ values and HBsAg confirmation test scores since the results of the Chi-Square test showed a $p$-value of $0.009(p<0.01)$.

Some $\mathrm{HBsAg}$ value ranges obtained were then tested using the Chi-Square test at $\alpha$ values of $1 \%$ and $5 \%$ as shown in Table 3 . In addition, the results of the HBsAg confirmation test revealed that among the thirty-two samples having reactive HBsAg value $(\geq 0.13)$, there were eighteen samples 
Table 2. Correlation of HBsAg values and HBsAg confirmation test scores

\begin{tabular}{lccc}
\hline \multirow{2}{*}{ HBsAg } & \multicolumn{2}{c}{ HBsAg confirmation test } & \multirow{2}{*}{$*$} \\
\cline { 2 - 3 } & $\begin{array}{c}\text { Reactive } \mathbf{n} \\
\text { (\%) }\end{array}$ & $\begin{array}{c}\text { Non-reactive } \\
\mathbf{n}(\%)\end{array}$ & \\
\hline Reactive & $18(56.2)$ & $14(43.8)$ & \\
Non- & $3(17.6)$ & $14(82.4)$ & 0.009 \\
reactive & & & \\
\hline
\end{tabular}

* Chi-Square test, $\mathrm{p}<0.01$

Table 3. Results of the Chi-Square test on $\mathrm{HBsAg}$ value ranges at $\alpha$ values of $1 \%$ and $5 \%$

\begin{tabular}{cccc}
\hline No & HbsAg value range & A & ${ }^{*} \mathbf{p}$ \\
\hline 1 & $0.11-0.17$ & $1 \%$ & 0.005 \\
2 & $0.12-0.17$ & $1 \%$ & 0.005 \\
3 & $0.13-0.17$ & $1 \%$ & 0.004 \\
4 & $0.13-0.18$ & $5 \%$ & 0.014 \\
5 & $0.13-0.20$ & $5 \%$ & 0.031 \\
6 & $0.13-0.50$ & $5 \%$ & 0.017 \\
7 & $0.14-0.35$ & $1 \%$ & $0 ., 005$ \\
\hline
\end{tabular}

confirmed to have reactive values (confirmed), while the other fourteen samples (43.8\%) had negative values (not confirmed). It indicated that there were fourteen $\mathrm{HBsAg}$ values $(43.8 \%)$ considered as false positives. Hua Shao et al., in his research concluded that the confirmation test was very important because it eliminated false positives. ${ }^{4}$

$\mathrm{HBsAg}$ actually is the first marker to appear during acute $\mathrm{HBV}$ infection. Positive $\mathrm{HBsAg}$ indicates the presence of HBV infection, which ultimately stimulates the production of anti-HBV antibodies. Before the anti-HBV and HBsAg antibodies could be detected in blood, it had been difficult to detect infections. High sensitivity tests, thus, are required to detect very low HBsAg levels so that HBV infection can be diagnosed early and more effective treatment can be possibly performed.

However, although the emergence of new methods to detect low levels of HBsAg is a significant advance in HBV diagnosis, the increased sensitivity is often accompanied by false-positive results. Therefore, reactive initial samples should be tested repeatedly with the same test or followed up with a confirmation test. This rigorous procedure then ensures the reliability of results. It has been reported that there was a difference in the sensitivity of various instruments and reagents to detect HBV serum markers. Differences in HBsAg detection were mainly found in samples with weakly reactive results, especially in the initial test. In addition, several fac- ous instruments and reagents to detect HBV serum markers. Differences in $\mathrm{HBsAg}$ detection were mainly found in samples with weakly reactive results, especially in the initial test. In addition, several factors that may cause false-positive results on HBsAg examination include HBsAg vaccination and individuals receiving Granulocyte-Colony Stimulating Factor (G-CSF). ${ }^{4,6,10}$

Moreover, the results also found that there were seventeen samples with non-reactive $\mathrm{HBsAg}$ values $(<0.13)$. However, after the HBsAg confirmation test, there were only fourteen samples (82.4\%) confirmed to have negative values (confirmed), while the other three samples (17.6\%) confirmed to have reactive (not confirmed). This indicated that there were three (17.6\%) negative false samples. The false negative results on HBsAg examination might due to a phase where there is a distance between HBV infection and HBsAg occurrence associated with limitation of devices used to measure HBsAg values. Similarly, a research conducted by Chen et al., also showed that some nonreactive samples in the initial test remained negative after confirmation tests, consequently, it could be concluded that confirmatory tests are only important for samples showing weakly reactive results in the initial test. ${ }^{4,5}$

Furthermore, in this research, the gray-zone ranges were obtained through the Chi-Square test at several intervals with $\alpha$ values of $5 \%$ and $1 \%$. The use of $\alpha=1 \%$ (minimum error rate) had indicated the HBsAg interval value of $0.13-0.17$ as the interval with the smallest meaning value, the $p$-value of $0.004(p<0.01)$. Therefore, it means that there was a very significant difference of reactive $\mathrm{HBsAg}$, gray zone and nonreactive values from $\mathrm{HBsAg}$ confirmation test results. As a result, this interval could be recommended to be used as the gray zone range that is the basis for conducting HBsAg confirmation tests. Unlike the results of this research, a research conducted by Hua Shao et al., analyzing HBsAg confirmation tests for VHB serum found that confirmatory tests were particularly important in Borderline (0.9-1 COI) or reactive ( $\geq 1-10 \mathrm{COI})$ results. ${ }^{4}$ The differences in the gray-zone range in this research from the previous research may be due to differences in the instruments, methods and HBsAg test value references used.

Unfortunately, repetition and confirmation tests require a lot of time and money. O'Brien in his study, then suggested that a radioimmunoassay method, confirmatory test will be not necessary if the $\mathrm{HbsAg}$ value is more than 6 . Meanwhile, for an enzyme immunoassay method, confirmation test will be not necessary if 
the $\mathrm{HbsAg}$ value is more than 6 . Meanwhile, for an enzyme immunoassay method, confirmation test will be not necessary if the initial HBsAg value is more than 1. O'Brien's research also concluded that HBsAg confirmation test was not required in highly reactive HBsAg values. ${ }^{4}$ Nevertheless, this research still has some limitations on the range of gray zone values obtained since those values were limited to temporary gray zone values determined by the researchers $(0.06-1 \mathrm{COI})$.

\section{CONCLUSION AND SUGGESTION}

Based on this research, the recommended gray zone range is $0.13-0.17 \mathrm{COI}$. It also can be concluded that the HBsAg confirmation test is important to perform, especially for reactive HBsAg values (weakly reactive), thereby reducing the time and cost in repeating HBsAg test. Nevertheless, further researches are expected to be conducted with more samples.

\section{REFERRENCES}

1. Kementrian Kesehatan Republik Indonesia. Situasi dan analisis hepatitis, Jakarta, Pusat data dan informasi kementrian kesehatan RI. 2014; 1-8.

2. Santiyoso A. Hepatitis virus akut, Dalam: Buku ajar IImu penyakit dalam, Ed Kelima., Jakarta, Interna Publishing, 2010; 644-652.
3. Lyn F. Hepatitis B. Center of disease control and prevention. VPD surveillance manual. $5^{\text {th }}$ Ed., 2011; 1-15. Available at: http://www.cdc.gov. Access on May 21, 2015

4. Shao H, Yan Li, Wan Zhou. Increased need for testing to confirm initial weakly reactive results for hepatitis $B$ virus surface antigen. Labmedicine. American Society for Clinical Pathology. 2012; 43(4): 15-17. Available at: www.medscape.com. Accessed on May 21, 2015

5. Dufour R. Hepatitis B Surface Antigen (HBsAg) Assay-are they good enough for their current uses?. Veterans Affairs Medical Center and George Washington, Washington DC, University Medical Center, 2006; 5(28): 1457-59.

6. Rysgard CD, Moris CS, Drees D, Bebber T, Davis SR, et al. Positive hepatitis $B$ surface antigen test due to recent vaccination: a persistent problem. BMC Clinical Pathology. Department of Pathology, University of Lowa Hospital and Clinics, Lowa City. 2012; 12(15): 1-6

7. Vidas ${ }^{\circledR}$ HBsAg Ultra Confirmation insert kit. France. 2012. Available at: www. Biomerieux.com. Access on May 21, 2015

8. Vidas $^{\circledR} \mathrm{HBsAg}$ insert kit. France. 2011. Available at: www. Biomerieux.com. Accessed on May 21, 2015

9. Hepatitis Bs Antigen (HBsAg) Neutralization (Confirmation). Laboratory Service Manual. 2004. Available at: http://www. Childrensmn.org. Accessed on May 21, 2015

10. Fletcher GJ, Manu Gnanamony, Joel D, Ismail AM, Subramani T, Abraham P. Do we need an in-house neutralization assay for confirmation 